Wellington Oliveira dos Santos Universidade Estadual de Goiás UEG

Email: wellpsico@gmail.com (D) https://orcid.org/0000-0002-3289-2483
Recebido em: 10/10/2017 Aprovado em: 10/12/2018

\section{Branquitude e negrofilia: o consumo do outro na educação para as relações étnico-raciais}

\author{
Wellington Oliveira dos Santos
}

\section{Resumo}

Este ensaio tem por objetivo propor o uso do termo negrofilia em análises sobre a branquitude. A reflexão vale-se do conceito de negrofilia (ARCHER-STRAW, 2000) que consiste em uma compreensão sobre o espaço de privilégio da branquitude que permite ao branco consumir intencionalmente a história, a cultura e o corpo do negro, usando o discurso politicamente correto - sem abrir mão dos seus privilégios. Primeiro é apresentada a origem e o uso do termo, que se situa na França do início do século XX, assim como esse pode ser inserido nos estudos sobre a branquitude. $\mathrm{Na}$ segunda parte deste ensaio, é apresentado um estudo de caso que ilustra de que forma a negrofilia está presente no sistema educacional de ensino e de formação de professores brasileiros, ainda que haja formação direcionada para a educação das relações étnico-raciais. Este ensaio, portanto, defende que a negrofilia pode ser identificada na formação de professores em disciplinas de Educação das Relações Étnico-Raciais, assim como em discursos que, supostamente, defendem a diversidade étnico-racial.

Palavras-chave: Branquitude. Negrofilia. Formação de professores. 


\begin{abstract}
Whiteness and negrophilia: the consumption of the other in education of race and ethnic relations

This essay aims to propose the use of the term negrophilia (ARCHERSTRAW, 2000) in analyses on whiteness. Whiteness privilege allows white people to intentionally consume the history, the culture and the bodies of black people using the politically correct discourse without renouncing to their privileges, and these attitudes consist in negrophilia. First, the origin and use of the term, which is situated in early twentieth-century France, is presented, as can be found in studies on whiteness. In the second part of this essay, a case study is presented that illustrates how negrophilia is

Keywords:

Whiteness.

Negrophilia.

Teacher

training.

present in the educational system of Brazilian teachers' education and training, even though there is training directed at the education of ethnicracial relations. The text argues that this can be noticed in the training of teachers for the education of race and ethnic relations, as well as in discourses that supposedly defend race and ethnic diversity.
\end{abstract}

\section{Resumen}

Palabras clave: Blancura.

Negrofilia.

Formación de professores.

\section{Blancura y negrofilia: el consumo del otro en educación de las} relaciones étnico-raciales

Este ensayo tiene por objetivo proponer el uso del término negrofilia (ARCHER-STRAW, 2000) en análisis sobre la blancura. El espacio de privilegio de la branquitud permite que el blanco consuma intencionalmente la historia, cultura y cuerpo del negro usando el discurso políticamente correcto, sin renunciar a sus privilegios, lo que consiste en negrofilia. Primero se presenta el origen y el uso del término, que se sitúa en Francia a principios del siglo XX, así como éste puede ser insertado en los estudios sobre la branquitud. En la segunda parte, se presenta un estudio de caso que ilustra de qué forma la negrofilia está presente en el sistema educativo de enseñanza y de formación de profesores brasileños, aunque haya formación dirigida a la educación de las relaciones étnico-raciales. El ensayo defiende que esto puede ser verificado en la formación de profesores en educación de las relaciones étnico-raciales, así como en los discursos que supuestamente defienden la diversidad étnico-racial. 


\section{Introdução}

Este ensaio objetiva propor o uso do termo negrofilia em análises sobre a branquitude. Nesta sendo, abrimos espaço para explicar a definição desse termo, apresentando-o a partir do que Petrine Archer-Straw (2000) cunhou. Negrofilia (do inglês negrophilia ${ }^{1}$ ) é o termo usado para explicar o consumo do corpo negro e de aspectos da negritude realizado por sujeitos brancos, que não reconhecem os privilégios de branquitude deles. Neste ensaio, compreendemos que a branquitude é o lugar de privilégios materiais e simbólicos ocupados pelos indivíduos reconhecidos como brancos em nossa sociedade racialmente hierarquizada (ver, p. ex., BENTO, 2003; CARDOSO, 2010b). Defendemos, por isso, que o espaço de privilégio da branquitude permite que o sujeito branco consuma de forma intencional a história, a cultura e o corpo do negro, usando o discurso politicamente correto - sem abrir mão dos privilégios que a branquitude garante. Explicamos, portanto, que a negrofilia pode ser verificada na formação de futuros professores para a educação das relações étnico-raciais, bem como em discursos que supostamente defendem a diversidade étnico-racial.

A elaboração deste ensaio foi influenciada a partir de uma experiência pessoal do autor no início do ano de 2017, quando fui (eu, homem negro) convidado a um programa da Rede Globo de Televisão. A referida emissora é conhecida por apresentar nos produtos televisivos elementos que dão destaque à estética ariana. A estética ariana é o conceito, segundo ótica de Joel Zito Araújo (2008), que denuncia a supervalorização dos traços das pessoas brancas (praticamente nórdicos) em detrimento dos traços racializados dos negros. Traços dessa estética ariana são vistos nas novelas, nos programas de culinária, nos programas infantis e em outras atrações da emissora ao longo do século XX. Atualmente, a Rede Globo parece engajada na pauta da diversidade, trazendo à grade horária da programação temas como: diversidade cultural, diversidade de gênero, diversidade de orientação sexual, diversidade racial, e etc. A pauta da diversidade ganhou, então, espaço em alguns dos produtos da emissora destinados ao público mais engajado e conectado à internet e às redes sociais: os jovens brasileiros. Esta faixa etária da sociedade brasileira é reconhecida como mais aberta às pautas progressistas e de diversidade, tendência observada no Brasil e em outros países (VALA; COSTA-LOPES, 2010).

A diversidade foi tema do programa que participei, o "Amor \& Sexo". No palco, apresentadora branca; atores brancos que participavam de uma novela convidados; músicos negros; dançarinos negros. Passávamos a integrar a cena do programa, também, como outros convidados: nós, duas mulheres negras e três homens negros, que representávamos as políticas de ação afirmativa no Ensino Superior e o sucesso delas. 
Posicionados no cenário do "Amor \& Sexo" de pronto colocamo-nos para sermos entrevistados.

Ou o que eu considero melhor afirmar: consumidos.

O conceito de consumo da cultura, da religião e do próprio corpo do negro/a não é novo. Em estudo sobre história da Arte, Petrine Archer-Straw (2000) usou o termo negrofilia para conceituar o interesse por parte da intelectualidade francesa pela cultura negra no início do século XX. A autora explica que entre os anos de 1920 e 1930, em Paris, intelectuais e artistas ligados aos movimentos de vanguarda tinham como passatempo frequentar bares onde o público, a música e a dança negra eram celebrados graças aos negros das antigas colônias francesas (ARCHER-STRAW, 2000). Tais intelectuais franceses ficaram fascinados com a liberdade de expressão maior dos corpos encontrados nestes locais. Dentre esses intelectuais circulava o termo négrophilie para se referirem ao ato de "metaforicamente consumir o chamado exótico mundo negro". Por essa razão, negrofilia foi adotado como forma de análise por Archer-Straw (2000). Como bem sabem os filhos de imigrantes africanos na França, atualmente, este tipo de valorização ficou restrita apenas aos círculos boêmios, não diminuindo o racismo ${ }^{2}$.

O capitalismo tornou a cultura e o corpo negro como objetos de consumo e, também, serviu de forma contraditória para, igualmente, satirizar e denunciar esta apropriação. Exemplos de produções audiovisuais que exploram o corpo e a cultura negra são inúmeros. Lançado em 2017, o filme "Get Out", do diretor, roteirista, ator e comediante Jordan Peele, narra o horror absurdo nos Estados Unidos, onde os brancos convivem em harmonia aparente com os negros, com o objetivo de consumir literalmente o corpo desses ${ }^{3}$. No Brasil, o documentário "Cidade de Deus - 10 anos depois" (BORGES; UCHÔA, 2015) apresenta parte da negrofilia. Produzido dez anos após o sucesso do filme, mostra aspectos das vidas dos atores envolvidos. A maior parte, jovens negros, de favelas do Rio de Janeiro. Apesar do dinheiro de participação na película e o sucesso para alguns, a vida voltou a mesma rotina para a maioria após o consumo dos corpos negros para entretenimento, como destaca o documentário de Borges e Uchôa (2015).

Esta negrofilia que consome o negro mantém o privilégio da branquitude concedido ao branco de ser uma "não raça", um ser humano por excelência. Manifestada com o que Quijano (2005) chama de colonialidade do poder, uma vez que o centro do saber ainda é eurocêntrico e, por isso, o consumo do outro é um consumo do estranho, do diferente.

Propomos investigar discursos que, supostamente, defendem a diversidade étnicoracial, ao se apropriarem dos negros e da cultura deles. Incluímos, também, os discursos de estudantes de cursos para formação de professores e a educação para as relações étnico- 
raciais. A negrofilia, portanto, é uma categoria de denúncia, inserida nos estudos sobre a branquitude. Por isso, neste ensaio partimos de uma definição de branquitude, para situarmos a negrofilia, e, em seguida, tratarmos de estudos sobre formação de professores e a educação para relações étnico-raciais, dando ênfase ao estudo de caso que realizamos.

\section{Branquitude e Negrofilia}

A atuação como docentes em disciplinas como Educação das Relações Étnico-Raciais, muitas vezes, pode gerar desconforto, uma vez que, quando falamos de racismo, falamos de grupos que são racializados no sentido que Fanon (1979) atribui a racialização do não-branco dentro da sociedade (negros, indígenas e ciganos, por exemplo), e deixamos explicitado que há um grupo que direta ou indiretamente é beneficiado por essa racialização, o grupo branco. Desconforto de ambos os lados: daqueles cujas suas peles e cujos passados trazem marcas da opressão; e daqueles que se veem como direta ou indiretamente beneficiados. É nestes últimos que os estudos sobre a branquitude têm foco.

Os primeiros estudos sobre a branquitude no Brasil podem ser localizados na metade do século XX, por exemplo, com os estudos de Guerreiro Ramos (OLIVEIRA, 2007; CARDOSO, 2010b). Nos anos de 1990, estudos sobre branqueamento organizados na Universidade de São Paulo e a influência dos estudos sobre a branquidade nos Estados Unidos revigoram os estudos sobre o espaço ocupado pelos brancos brasileiros (OLIVEIRA, 2007).

Estudos sobre cursos de formação de professores e a educação para as relações étnicoraciais podem ser inseridos nos estudos sobre a branquitude porque, mesmo com o aumento da participação de estudantes negros no Ensino Superior, que se deu graças às políticas de ação afirmativa e ao aumento de vagas na graduação, a maioria dos professores em formação nas licenciaturas e cursos de pós-graduação é branca. Sendo assim, as relações étnico-raciais devem ser analisadas não apenas da perspectiva dos grupos afetados pelo racismo, o que seria uma abordagem unilateral de acordo com Cardoso (2010a), mas também da perspectiva do grupo branco. A própria categoria negro, no Brasil, é construída também pelo olhar do branco, o "eu" que projeta muitas coisas (geralmente negativas) nesse "outro" (CARONE, 2003).

De acordo com Carone (2003) na sociedade brasileira, geralmente, um branco é tão somente o representante de si mesmo, um indivíduo. A raça branca não faz parte dessa individualidade no olhar do outro. Um negro representa uma coletividade racializada em bloco - cor e raça é ele mesmo - no olhar do "eu" branco. Raça tende a ser usada como estigma, como diz Goffman (1988). A construção de estigmas acontece com a categorização 
das pessoas em sociedade. O sujeito que carrega o estigma é um "outro" social, que é tratado no discurso como se não pertencesse à humanidade (GOFFMAN, 1988).

A branquitude garante privilégios ao branco, já que de acordo com Bento, analisando o processo de branqueamento, real ou simbólico, que o negro faz uso para se aproximar do branco, "[este] pouco aparece, exceto como modelo universal de humanidade, alvo da inveja e do desejo dos outros grupos raciais não-brancos e, portanto, encarados como não tão humanos". (2003, p. 25).

Nesse ponto de vista, a própria reivindicação de políticas de valorização da história e cultura afro-brasileira e indígena, presentes em disciplinas de Educação das Relações ÉtnicoRaciais podem ser vistas pela branquitude como uma tentativa dos "não humanos" (os estigmatizados, como afirma GOFFMAN, 1988) de ocupar os espaços dos humanos por excelência.

Ao falarmos de racismo, devemos sempre destacar o lugar do branco, do que é beneficiado pela desigualdade, e isso igualmente para os estudantes brancos, afinal "evitar focalizar o branco é evitar discutir as diferentes dimensões do privilégio. Ainda que esteja em situação de pobreza, o branco terá o privilégio simbólico da brancura, o que não é pouca coisa". (BENTO, 2003, p. 27).

Quando deixamos de lado a análise do outro polo da discriminação, acabamos por confirmar o falso discurso de que o racismo é um problema dos grupos afetados, portanto somente eles devem ser estudados. Dessa forma, somente eles permanecem como o outro, como o objeto a ser dissecado (BENTO, 2003; CARDOSO, 2010a).

Evitar falar do branco é evitar falar de todos os privilégios que o grupo possui em uma sociedade racializada como a nossa (brasileira). Para Bento:

\footnotetext{
O silêncio, a omissão, a distorção do lugar do branco na situação das desigualdades raciais no Brasil tem um forte componente narcísico, de autopreservação, porque vem acompanhado de um pesado investimento na colocação desse grupo como grupo de referência da condição humana (2003, p. 30).
}

Esse narcisismo pode ser visto na supervalorização do corpo branco feita pela mídia brasileira que, em seus jornais, suas novelas, seus seriados, e os programas mais recentemente exibidos na internet valem-se quase que exclusivamente de pessoas brancas, mesmo sendo a população brasileira composta por mais da metade de pretos e pardos. Quando os negros aparecem nessas mídias como no caso de um programa em que participei e citei anteriormente sobre estudantes negros no Ensino Superior, esses estudantes são tratados como objetos de admiração. Conforme Bento, explicando o conceito psicanalítico de narcisismo: 
Freud identifica a expressão do amor a si mesmo, ou seja, o narcisismo, como elemento que trabalha para a preservação do indivíduo e que gere aversões ao que é estranho, diferente. É como se o diferente, o estranho, pusesse em questão o "normal", o "universal" exigindo que se modifique, quando autopreservar-se remete exatamente à imutabilidade (2003, p. 30).

Portanto, falar de racismo, relações étnico-raciais e lugares ocupados por negros e brancos na sociedade e na educação é pôr em xeque este narcisismo. Esta autora destaca que, ainda entre as pessoas mais engajadas, há problemas sociais em reconhecer o racismo o que é uma dificuldade, principalmente, para os brancos (BENTO, 2003). No estudo dela, é analisada uma disciplina para formação sobre relações étnico-raciais na qual a docente notou que os estudantes tendiam a relativizar o problema do racismo quando o debate incomodava. Afinal, se os negros são discriminados, os gordos, da mesma forma, são. Para a pesquisadora, a relativização leva a uma negação da realidade do racismo:

Essa negação aparece frequentemente quando não queremos enfrentar uma determinada realidade, quer porque não desejamos nos ver como sujeitos de determinados tipos de ações, quer porque temos interesses nem sempre confessáveis em jogo, ou ainda porque aceitar a realidade do racismo significa ter que realizar mudanças. (2003, p. 148).

Isso porque participar de debates sobre relações raciais possibilita perceber os espaços de privilégio ocupados por brancos (branquitude) em nossa sociedade racializada. Em todo caso, os brancos engajados em causas sociais que participam de debates sobre as relações étnico-raciais estariam situados em um tipo de branquitude crítica. Cardoso (2010a) argumenta que a branquitude pode tanto ser crítica, quanto acrítica. No primeiro caso, ela desaprova publicamente o racismo. No segundo caso, a branquitude acrítica não reconhece o racismo e argumenta que ser branco é uma condição de superioridade (CARDOSO, 2010a). O autor reconhece que a branquitude crítica desaprova publicamente o racismo, porque o brasileiro tem preconceito em ter preconceito (CARDOSO, 2010a). Portanto nem sempre o que é desaprovado publicamente coincide com o mundo privado.

Defendemos que entre os privilégios da branquitude crítica definida por Cardoso (2010a) está a possibilidade de consumo da cultura e do corpo do negro, em nome de um suposto engajamento. Para denunciar este privilégio, retomamos o uso feito por Archer-Straw (2000) do termo negrofilia e ampliamos o seu alcance.

Dizemos que negrofilia é o consumo da história, da cultura e do corpo do negro para responder às críticas do politicamente correto, sem abrir mão dos privilégios da branquitude. Assim como Archer-Straw (2000), adotamos o conceito de modo a denunciar esse consumo do outro feito pelos brancos, consumo que não ajuda a superar as desigualdades historicamente construídas, porém satisfaz o ego branco. Em uma análise com conceitos 
psicanalíticos, podemos afirmar que dois instintos básicos estão em atuação por parte do ego branco: a incorporação do objeto de desejo, por meio da pulsão de sexualidade, e a destruição do desconhecido e temido, por meio da pulsão de agressividade. Assim, ao consumir o negro, o branco estaria em situação de diminuição da ansiedade egóica diante do julgamento social de não estar engajado com as lutas do antirracismo. Ele também satisfaz a necessidade de controlar o outro, tornando-o algo familiar. Essa incorporação do objeto não será suficiente para superar práticas racistas se o ego branco não reconhece e supera privilégios narcisistas de branquitude dele.

Além disso, as defesas da branquitude são expressas no discurso da mestiçagem, já que tal discurso tende a ser evocado quando os militantes negros reivindicam políticas reparatórias baseadas em critérios raciais. De acordo com Oliveira (2007), em seu estudo sobre representações de branquitude entre indivíduos brancos, a partir das denúncias do movimento negro e outros fatores, os brancos brasileiros tendem a adotar uma vigilância em nome do politicamente correto, usando o discurso de que todos os brasileiros são mestiços e, por vezes, apelam para possíveis ancestrais negros na família, sem abrir mão de seu privilégio.

Negrofilia, como parte da branquitude, está entrelaçada por outros níveis de desigualdade construídos social e historicamente em nossa sociedade, como os de classe social e gênero. Basta lembrarmos, por exemplo, da pirâmide sócio-racial brasileira, do topo para a base, e como ela influência nos relacionamentos interpessoais: homem branco, seguido de mulher branca, seguida de homem negro, com a mulher negra na base ${ }^{4}$. Portanto, os homens brancos estão em melhores condições de tomar todos os outros membros como objetos - quase literalmente; a mulher branca, ainda que abaixo do homem branco em termos de privilégio, ainda goza de algumas vantagens em relação ao homem negro e a mulher negra; o homem negro ocupa certos espaços de poder pela sua posição de gênero diante da mulher negra; e para a mulher negra resta a base da pirâmide, reproduzida em terras brasileiras desde quando seu corpo foi escravizado para fins de procriação, divertimento e, até mesmo, o uso na forma de empregadas domésticas (como sabemos, a figura da doméstica é herança direta do passado escravista de uma sociedade em que alguns ainda acreditam estarem vivendo na casa grande).

Sendo a negrofilia o consumo da história, cultura e corpo do negro, sem abrir mão dos privilégios da branquitude, podemos falar em uma "brancofilia", em sentido diametralmente oposto? Não, uma vez que o privilégio de branquitude é um privilégio de não-raça (BENTO, 2003; CARDOSO, 2010a), o negro (ou outro racializado) não consome a cultura e história do branco como se fosse um outro, um estranho, e sim como se fosse o universal. Não se fala em 
história e cultura europeia ou religiões eurobrasileiras, por exemplo. Um conceito próximo seria o de apropriação cultural. Contudo, a apropriação cultural cabe mais ao campo da estética (consumo de itens da cultura afro ou adotar tranças raízes, por exemplo, geralmente sem consciência das origens) do que um consumo intencional do corpo negro e tomada de espaço, característica da negrofilia, coberta pelo politicamente correto.

(Abrimos parênteses, de forma literal, para citar e destacar um exemplo da política nacional. Durante as eleições de 2018, o então candidato à presidência Jair Bolsonaro, de extrema-direita, aparecia em suas propagandas nas redes sociais ao lado do então candidato a deputado federal pelo Rio de Janeiro Hélio Lopes, homem negro conhecido pelo apelido de Hélio Negão. A presença de Hélio era uma resposta de Bolsonaro às críticas da esquerda de que era um candidato racista ${ }^{5}$. Ou seja, justamente um candidato que criticava o politicamente correto, em um ato de negrofilia, colocou um corpo negro ao lado para se defender e tentar conquistar votos da população negra. Com o término das eleições, a composição ministerial esboçada por Bolsonaro mostrava sua real visão de mundo: a maioria homens brancos e militares).

Assim como outros aspectos da branquitude, reconhecer a negrofilia pode gerar resistência. A resistência pode se manifestar em forma de culpa, de impotência, de agressividade; por isso, antes de cometer o erro de simplesmente excluir o branco dos debates, é preciso apontar caminhos para a mudança (BENTO, 2003). Assim, se a branquitude é uma porta de vidro, usando a metáfora de Piza (2003), a mudança muitas vezes tem que ser feita com cautela, evitando as defesas narcisistas.

Em estudo citado anteriormente, Bento (2003) apresentou como a branquitude pode se manifestar em cursos de formação de professores. Para apresentarmos exemplos da negrofilia, igualmente partirmos da análise de uma disciplina de formação de professores. Por isso faz-se necessário breve consideração sobre formação de professores para a educação das relações étnico-raciais e a branquitude.

\section{Considerações sobre formação de professores, branquitude e negrofilia}

Em 2003 a Lei n. 10.639 (BRASIL, 2003), que modifica o Art.26 da Lei de Diretrizes e Bases da Educação Nacional (LDB) de 1996, foi sancionada, sendo mais incisiva do que o texto anterior da LDB - que trata a questão racial de maneira vaga (DIAS, 2004). O novo texto assumiu a posição de afirmação da História e Cultura Afro-brasileira, ao explicitar a obrigatoriedade de seu ensino. Por isso, Gomes considera que a Lei, assim como as Diretrizes que a guiam, foram conquistas, porém: 
[...] entram em confronto com as práticas e com o imaginário racial presentes na estrutura e no funcionamento da educação brasileira, tais como o mito da democracia racial, o racismo ambíguo, a ideologia do branqueamento e a naturalização das desigualdades raciais. (GOMES, 2010, p. 8).

O racismo ambíguo que Gomes cita pode ser observado em pesquisas de opinião sobre o racismo nacional. Em 2017, o IBOPE divulgou pesquisa na qual de cada 10 entrevistados, apenas 2 admitiram serem preconceituosos. Ao mesmo tempo em que $83 \%$ assumiram ter feito comentários racistas, machistas ou homofóbicos ${ }^{6}$.

Outros exemplos dos problemas enfrentados pela legislação antirracista podem ser vistos no trabalho de Braga (2009), que faz uma análise das Leis n. 10.639 e n. 11.645, e constata que a aplicação das Leis muitas vezes vem sendo feita por meio da folclorização:

A alternativa da folclorização da cultura afro-indígena é a porta mais usada,
atualmente. É através dessa porta que colégios e estudantes estão tendo acesso e
contato com as Leis $\mathrm{n}^{\circ} 10.639 / 11.645$. Nas datas-comemorativas essa folclorização
fica mais evidente. Para combater essa folclorização é preciso formação continuada
e em serviço, capacitação e renovação constantes para o(a)s professore(a)s, do
material didático e das atividades extraclasse. (BRAGA, 2009, p. 138).

A folclorização de que trata Braga é um exemplo de negrofilia: consome-se o negro apenas em datas específicas do calendário escolar, supostamente respondendo uma demanda antirracista, sem considerar a preponderância do branco no resto do ano letivo. Buscando denunciar e superar esses e outros entraves, a formação de professores, com o objetivo de trabalharem em conformidade com a Lei n. 10.639/03, é, igualmente, tema de trabalhos acadêmicos. Por exemplo, Deus (2012) discute os problemas para a implementação da referida Lei sem que as universidades e centros de formação alterem seus currículos. A universidade, que, frequentemente, utiliza instrumentos epistemológicos de origem eurocêntrica (ver o conceito de colonialidade do poder, de QUIJANO, 2005), não fornece condições para entendimentos diversos da realidade do país, um dos objetivos do estudo de história e cultura afro-brasileira (DEUS, 2012). Gonçalves (2011) em pesquisa feita em conjuntamente com professores de Ituiutaba/MG, concluiu que mesmo com o reconhecimento da legislação existente sobre educação para relações étnico-raciais, esta somente é concretizada na prática por meio do compromisso assumido pelos professores. $\mathrm{O}$ compromisso resulta, entre outras coisas, da história de vida desses professores, com aspectos relevantes de identidade profissional e pessoal que os identifica com o tema (GONÇALVES, 2011).

Em 2009 foi aprovado o Plano Nacional de Implementação das Diretrizes Curriculares Nacionais para a Educação das Relações Étnico-Raciais e para o Ensino de História e Cultura Afro-Brasileira e Africana (BRASIL, 2009). O plano estabelece, entre as ações das 
instituições de Ensino Superior, a inclusão de conteúdos e disciplinas relacionados a educação das relações étnico-raciais nos cursos de graduação, salientando que devem desenvolver nos estudantes de licenciatura e cursos de formação de professores habilidades e atitudes para contribuir para a educação para relações étnico-raciais (PASSOS, 2014). Apesar das diretrizes e do plano nacional, Passos (2014), que realizou pesquisa sobre as relações étnico-raciais nos projetos pedagógicos de licenciaturas de História e Pedagogia em Santa Catarina, constatou que o conteúdo ainda é pouco abordado, principalmente nos cursos de Pedagogia.

Como dito anteriormente, realizamos estudo sobre formação de professores em uma disciplina de Educação das Relações Étnico-Raciais, neste caso tendo como foco estudantes de graduação (licenciatura). Aqui apresentamos de forma breve o estudo. Participavam das aulas 24 estudantes (todas mulheres) do segundo e terceiro ano de Pedagogia de uma universidade pública de Goiás, no ano de 2017. A disciplina era semestral e optativa, e constatamos que a maioria das estudantes frequentava as aulas por interesse no tema. Aplicamos um breve questionário para levantamento de raça/cor das estudantes, conforme as categorias do IBGE. Com relação à raça/cor autodeclarada, 37,5\% brancas; 41,7\% pardas; 12,5\% pretas; e 8,3\% amarelas. Considerando a participação dos grupos de cor/raça no estado de Goiás, o percentual de pretas, pardas e brancas foi próximo ao da população geral do estado (BRASIL, 2015). A autodeclaração de amarelas (8,3\%) chamou a atenção, tendo em vista que a participação do grupo no Brasil é de cerca de $2 \%$. O grupo amarelo, de acordo com a metodologia do IBGE, é reservado para os descendentes de asiáticos, principalmente japoneses, coreanos e chineses. Porém, o que observamos durante a aplicação do questionário foi certa confusão com a cor da pele "amarela de sol". Outro ponto relevante: durante a resposta a este item do questionário, algumas estudantes perguntaram entre elas a respeito do uso do termo pardo. Elas entendiam o uso do termo branco apenas para mulheres brancas de olhos e cabelos claros. Como o item era autodeclarado, optamos por não interferir.

Na primeira aula da disciplina Educação das Relações Étnico-Raciais, organizamos as estudantes em uma atividade na qual elas eram convidadas a escrever, em uma folha de papel, o que esperavam dessa disciplina. O objetivo foi verificar o conhecimento das estudantes sobre o tema, bem como possíveis expectativas.

De forma geral, as respostas das estudantes sobre "o que esperam da disciplina" podem ser classificadas em três categorias (optamos por usar nomes fictícios para as estudantes):

1) Conhecimento sobre raça e racismo. Por exemplo, alguns trechos dos depoimentos das alunas: "Compreender melhor como se dá a convivência entre diferentes povos" (Ana, 26 anos, branca); "Conhecer melhor sobre esse conteúdo que sempre foi um tabu na sociedade, 
tanto no âmbito educacional como profissional" (Maria, 25 anos, parda). "Entender o racismo" (Beatriz, 25 anos, parda).

2) Existência do sistema de cotas. Por exemplo, alguns trechos dos depoimentos das alunas: "Como entrei na [universidade] através de cota de negros gostaria muito de entender" (Bárbara, 24 anos, preta); "Compreender como é feita a divisão de cotas nas universidades e quem pode usufruir da mesma." (Patrícia, 25 anos, parda); "Saber o porque que existe cotas na universidades, se todos tem (sic.) o mesmo direito" (Viviane, 32 anos, parda).

3) Necessidade prática da sala de aula. Por exemplo, alguns trechos dos depoimentos das alunas: "Como explicar para uma criança por que uma é branca e a outra tem a pele mais escura?" (Ana, 26 anos, branca); "Saber lidar com situações a qual estaremos presenciando no cotidiano" (sic) (Gabriela, 25 anos, branca); "Saber como agir com as crianças que traz esse preconceito de casa" (sic) (Bárbara, 24 anos, branca); "Como abordar o assunto no cotidiano escolar" (Bianca, 24 anos, parda).

Após as escritas do que as alunas esperavam da disciplina, organizamos debate sobre raça, racismo e relações étnico-raciais na educação. Sobre o racismo, ocorreram momentos em que demonstraram confusão entre os conceitos de racismo e preconceito, o que era indicado na primeira categoria de respostas escritas: seria preconceito contra gays um tipo de racismo? E a discriminação por ser obeso é o mesmo tipo de discriminação contra negros? Bento (2003) e também Munanga (2003) alertam para essa relativização do racismo, o que em trabalhos anteriores (SANTOS, 2012) chamamos de banalização das diferenças: se tanto negros quanto obesos, baixinhos, etc., sofrem discriminação equivalente, não haveria necessidade, portanto, de reivindicar políticas de ação afirmativa em nome do grupo negro. A banalização das diferenças atua no discurso para manter espaços de poder, diminuindo ou eliminando as reivindicações dos grupos afetados pela dominação.

O conhecimento sobre raça, racismo e relações étnico-raciais adquirido na disciplina pode ser, em alguns casos, uma preocupação da branquitude crítica (CARDOSO, 2010a). Na terceira categoria de respostas escritas, necessidade prática da sala de aula, a maioria das expectativas escritas tinham sido feitas por estudantes brancas. Aqui evidenciamos a negrofilia. De certa forma, para a branquitude das estudantes, participar de uma discussão sobre relações étnico-raciais seriam um modo de responder ao politicamente correto e garantir boas atuações em sala de aula.

Além disso, as estudantes brancas defenderam a existência do "racismo contra brancos" para se contrapor ao racismo existente contra os grupos racializados, o que nos parece uma estratégia da branquitude, em seu narcisismo, em sua autopreservação (BENTO, 
2003). O sentir-se ameaçado em seu espaço de privilégio evoca o discurso de que igualmente sofrem ataque. Estratégia recorrente no discurso do racismo brasileiro: ao mesmo tempo em que o branco usa o discurso para estar no patamar de igualdade do negro, quando diz que também sofre racismo, retira a possibilidade do negro ter o discurso para argumentar em defesa própria, estando em patamar de diferença. Ou seja, a branquitude inicialmente impedia que os estudantes tomassem consciência dos seus privilégios raciais.

O racismo na escola foi tratado, no debate, a partir da responsabilidade da família da criança, evitando a responsabilidade da própria instituição escolar: "a criança negra já vem com a autoestima de casa" (sic) (Ana, 26 anos, branca). O mesmo foi observado por Carvalho (2008), de outro ponto de vista. De acordo com os professores, as famílias dos estudantes negros deveriam prepará-los para combater o racismo, o que isenta os professores de qualquer conflito racial em sala de aula (CARVALHO, 2008). Neste caso, estaríamos diante de um mecanismo de defesa, no estilo clássico da psicanálise, que projeta a responsabilidade de algo negativo para o outro e livra o ego de reconhecer sua responsabilidade. Trata-se de um privilégio da branquitude considerar o racismo um problema do negro.

Também aspectos do discurso que suavizavam a raça foram notados. Um dos discursos foi o uso do termo moreno para se referir ao negro, de início, como uma estudante colocou: "eu namorei um rapaz bem moreno, moreno [olha para o professor], negro mesmo" (sic) (Carolina, 25 anos, branca), ao mesmo tempo em que discordava da necessidade de políticas de ações afirmativas baseadas em critérios raciais. Ou seja, o fato de um branco ter relacionamentos com negros (consumo de corpos), na lógica da branquitude, é indício de que o racismo não é tão relevante assim. Então qual seria a razão de frequentar uma disciplina Educação das Relações Étnico-Raciais? Interpretamos este consumo de história e cultura do negro para fins politicamente corretos, sem reconhecer seus privilégios de branquitude, como negrofilia.

Outro aspecto do discurso que suaviza a raça: algumas estudantes, reconhecidas como negras pelas colegas, não se colocavam como tal, preferindo o uso do termo "misturada" (Bruna, 31 anos, preta), afirmando que em suas famílias existiam negros, indígenas e brancos, ainda que dentro das categorias do IBGE optassem pela cor preta. Sendo o estigma racial depreciativo (GOFFMAN, 1988), elas preferiram fugir do termo.

Sobre as cotas para o Ensino Superior, uma das categorias que surgiram nas expectativas escritas, algumas estudantes brancas falaram de "esforço pessoal" para questionar a existência das cotas. Na lógica dessas alunas, bastaria, afinal, esforço para ingressar na universidade. Esse, também, é um movimento de preservação de privilégios do ego (BENTO, 2003), ao não reconhecer os espaços ocupados pelo branco na sociedade e a 
estrutura que impede os grupos racializados de ter as mesmas oportunidades. Como mostrou o estudo de Schucman (2014), mesmo quando reconhecem à existência de racismo, os brancos podem rejeitar as políticas de ações afirmativas baseadas em critérios raciais, como as cotas no Ensino Superior, para manter as vantagens na competição social. Neste sentido, refletem parte das opiniões negativas veiculadas durante anos na grande mídia sobre as cotas (como os estudantes universitários da pesquisa de SANTOS; FERRARINI, 2013), mesmo com a existência de dados que indicam os sucessos das ações afirmativas.

Com o decorrer das aulas da disciplina Educação das Relações Étnico-Raciais, trabalhamos com leitura de textos teóricos sobre raça, racismo e educação das relações étnicoraciais; história do movimento negro e legislação educacional antirracista; participação de mulheres negras na educação; espaços de negros e brancos na mídia; e estudo de pesquisas com dados estatísticos sobre participação de negros e brancos no Ensino Superior, no mercado de trabalho e na educação geral. Os textos eram indicados antes de cada aula, e debatidos em sala, em pequenos grupos. Desenvolvemos reflexões sobre possibilidades da Lei n. 10.639/03 na Educação Infantil e Ensino Fundamental, a partir de textos e atividades práticas. Além disso, debatemos em sala filmes como "Vista minha pele" e "Cores \& Botas".

Após as aulas, eram retomadas perguntas sobre a importância da educação para as relações étnico-raciais que eram respondidas por escrito e, posteriormente, debatidas. Aspectos sobre o tratamento desigual enfrentado por crianças negras no sistema educacional, ausentes nas reflexões iniciais, surgiram, bem como as limitações de um currículo centrado na cultura europeia. As estudantes também questionaram e debateram sobre importância de professores negros em sua formação, o que indica que determinados aspectos da branquitude, quando discutidos, podem ser criticados pelos membros do grupo beneficiado. A partir das respostas das estudantes foi possível constatar que durante as aulas, inicialmente encaradas como estudos sobre o "negro", o "outro", um exemplo de negrofilia, passaram a ser entendidas como estudos sobre as relações étnico-raciais brasileiras e seus efeitos na educação.

Colocar as legislações educacionais antirracistas, como a Lei n. 10.639/03 e as políticas de ação afirmativa no Ensino Superior em prática é um dos desafios para intelectuais e militantes negros. Gomes (2010) argumenta que a educação, pelo seu papel estratégico na sociedade, esteve presente nas ações e lutas do movimento negro brasileiro nos séculos XIX, XX e XXI. Isso porque:

Os ativistas do Movimento Negro reconhecem que a educação não é a solução de todos os males, porém, ocupa um lugar importante nos processos de produção de conhecimento sobre si e sobre "os Outros", contribui na formação de quadros 
intelectuais e políticos e é constantemente usada pelo mercado de trabalho como critério de seleção de uns e exclusão de outros. Além disso, a educação, no Brasil, é um direito constitucional conforme o artigo 205 da Constituição Federal (1988). Porém, todas as pesquisas oficiais realizadas nos últimos anos apontam como o campo educacional tem produzido e reproduzido no seu interior um quadro de desigualdades raciais. (GOMES, 2010, p. 4).

É a partir do reconhecimento do espaço de poder que a educação ocupa que os ativistas negros(as) se mobilizam em torno das pautas educacionais. Por isso, buscam ter o privilégio da palavra - o discurso para situar suas demandas. No século XXI, a Conferência de Durban possibilitou o reforço da bandeira, por parte do movimento negro brasileiro, da busca pela igualdade a partir da valorização da diversidade, no reconhecimento e no respeito às diferenças. Com a criação da Secretaria de Políticas de Promoção da Igualdade Racial (Seppir) (2001) e da Secretaria de Educação Continuada, Alfabetização, Diversidade e Inclusão (Secadi) (2004) e aprovação da Lei n. 10.639/03, o debate aprofundou-se (GOMES, 2010). Uma dificuldade a ser enfrentada é que ainda que a alteração da LDB garanta legalmente uma política de ação afirmativa, tanto a Seppir quanto a Secadi dependem de ações governamentais, o que significa que suas atuações podem variar de acordo com os pontos de vistas ideológicos dos partidos no poder. Com a eleição de um presidente assumidamente contrário as ações afirmativas para a população negra em 2018, o futuro dessas secretarias permanece incerto.

\section{Considerações finais}

A negrofilia é o consumo intencional da história, cultura e corpo do negro usando o discurso politicamente correto, realizada por brancos, sem abrir mão dos privilégios da branquitude. Ao adotarmos tal conceito para as análises de branquitude, ele pode levantar questões. Aqui buscamos responder provisoriamente duas possíveis. Primeira questão: a própria definição de branquitude já levanta um debate considerável (CARDOSO, 2010a), portanto adicionar mais um elemento contribuirá para o debate? Segunda questão: não estaria o termo contribuindo para acirrar os conflitos identitários, afastando possíveis aliados?

Respondendo à primeira questão. Não cabe neste texto debater o uso de branquitude, entretanto, enquanto conceito para crítica de privilégios étnico-raciais, entendemos que negrofilia contribui com a análise da manutenção de desigualdades baseadas na branquitude, pois é a relação desigual de poder que permite o consumo do outro no racismo cordial brasileiro.

Respondendo à segunda questão. A negrofilia é um risco possível nas relações entre negros e brancos em nossa sociedade marcada pelas hierarquias raciais. Ainda assim reconhecê-la não impede que os brancos façam parte das discussões sobre relações étnico- 
raciais de maneira crítica. Afinal, em tempos de bolhas de opinião nas redes virtuais, provavelmente, aqueles que fazem parte dos círculos de apoio às causas dos(as) negros(as) são justamente os engajados em diversas reivindicações progressistas, estejam eles entre os participantes de programas de televisão ou entre professores dos cursos de formação, por exemplo.

As resistências às mudanças nos discursos, principalmente aos relacionados ao papel dos professores como (re)produtores de racismo, podem ser originárias da branquitude. Sendo assim, uma meta possível para estudiosos e militantes da educação das relações étnico-raciais é apresentar ao sujeito branco esse ponto de poder no qual se encontra, não com o objetivo de culpabilizar, e sim com o objetivo de diálogo para mudança. A educação para as relações étnico-raciais, na Educação Infantil, Ensino Fundamental, Ensino Médio ou Ensino Superior não devem depender apenas do compromisso de professores engajados com as pautas antirracistas (principalmente professores negras/os): ela deve ser parte constituinte da formação, reflexão e ação de todos os professores.

Professores(as) brancos(as) que frequentam cursos de formação e disciplinas sobre educação para as relações étnico-raciais devem se reconhecer como privilegiados, capazes de apoiar a luta dos negros (apoiar sim, mas não como protagonistas), de maneira crítica. Devem estar cientes de seus papeis de poder, e de como o consumo do outro de maneira não crítica pode resultar, em última análise, na continuidade de relações de poder.

\footnotetext{
Notas

${ }^{1}$ Optamos por usar o termo negrofilia em sua grafia no português, como faz a obra de Livio Sansone (2004) ao citar a pesquisa de Archer-Straw.

${ }^{2}$ A pesquisa de Archer-Straw permite um paralelo entre os conflitos raciais franceses do início do século XX e o multiculturalismo atual que não impede os negros descendentes de africanos de sofrerem com o racismo. Disponível em: <https://www.theguardian.com/books/2000/sep/23/features.weekend >. Acesso em 09 out. 2017. ${ }^{3}$ Aspecto relevante em Get Out é que os brancos que consomem o outro são abertamente liberais democratas, eleitores de Obama e fãs de ídolos negros do esporte. No contexto dos Estados Unidos, liberais são mais próximos de pautas progressistas do que os conservadores republicanos. Analisamos as relações étnico-raciais desse filme em outro artigo (SANTOS, 2018).

${ }^{4}$ De acordo com o IPEA, mulheres negras ganham em média menos de $40 \%$ do salário de um homem branco no Brasil. Disponível em: <https://www.geledes.org.br/brasileira-negra-ganha-menos-de-40-do-salario-debrasileiro-branco-diz-ipea/ > . Acesso em 09 out. 2017.

${ }^{5}$ Críticas baseadas nas declarações do candidato atacando quilombolas. Bolsonaro também atacou outros grupos minoritários durante sua carreira política, como as mulheres, os indígenas e os homossexuais. Disponível em: $<$ https://brasil.elpais.com/brasil/2018/10/06/politica/1538859277_033603.html >. Acesso em 01 dez. 2018.

${ }^{6}$ A pesquisa feita pelo IBOPE foi encomendada pela Ambev-Skol, grupo de cervejarias que, contraditoriamente, usa em suas publicidades majoritariamente homens brancos e jovens como consumidores e/ou mulheres brancas e jovens como objeto de sensualidade. Disponível em: $<$ http://brasil.estadao.com.br/noticias/geral,so-2-em-cada10-brasileiros-admitem-ser-preconceituosos-diz-pesquisa-do-ibope,70002034390 > . Acesso em 09 out. 2017.
} 


\section{Referências}

ARAÚJO, Joel Zito. O Brasil negro e suas africanidades no campo das artes e linguagens. In: Congresso Brasileiro de Pesquisadores Negros, 4, Salvador, 13 a 16 de setembro de 2006. Anais... Salvador, 2006.

ARCHER-STRAW, Petrine. Negrophilia: Avant-Garde Paris and Black Culture in the 1920s. New York: Thames \& Hudson, 2000.

BENTO, Maria A. S.. Branquitude: o lado oculto do discurso sobre o negro. In: CARONE, Iray e BENTO, Maria A. S. (orgs.). Psicologia social do racismo: estudos sobre branquitude e branqueamento no Brasil. Petrópolis: Vozes, 2003, p. 147-162.

BRAGA, Alexandre F. Educação Afro-Indígena: caminhos para a construção de uma sociedade igualitária. Revista FACED, Salvador, n. 15, p. 127-141, jan./jul. 2009.

BRASIL. IBGE. Pesquisa nacional por amostra de domicílios, 2015. Disponível em: $<$ https://ww2.ibge.gov.br/home/estatistica/populacao/trabalhoerendimento/pnad2015/default.shtm>. Acesso em: 19 maio 2018.

BRASIL. Lei $\mathbf{n}^{\mathbf{0}} 10.639$ de 09 de janeiro de 2003. Disponível em: http://www.planalto.gov.br/ccivil_03/leis/2003/L10.639.htm. Acesso em: 26 jun. 2017.

BRASIL Plano nacional de implementação das diretrizes curriculares nacionais para a educação das relações étnico-raciais e para o ensino de história e cultura afro-brasileira e africana. Brasília: SEPPIR; MEC/SECAD, 2009.

CARDOSO, Lourenço. Branquitude acrítica e crítica: a supremacia racial e o branco anti-racista. Revista Latinoamericana de Ciencias Sociales, Niñez y Juventud, Vol. 8 no. 1, p. 607-630 jan.jun., 2010a.

CARDOSO, Lourenço. Retrato do branco racista e anti-racista. Reflexão e Ação, v. 18, n. 1, p. 46-76, jan./jun., 2010b.

CARONE, Iray. Breve histórico de uma pesquisa psicossocial sobre a questão racial brasileira. CARONE, Iray e BENTO, Maria A. S. (orgs.). Psicologia social do racismo: estudos sobre branquitude e branqueamento no Brasil. Petrópolis: Vozes, 2003, p. 13-23.

CARVALHO, Marília. Quem é negro, quem é branco: desempenho escolar e classificação racial de alunos. Revista Brasileira de Educação, p. 77-95, jan./fev./mar./abr., 2005.

CIDADE DE DEUS: 10 ANOS DEPOIS. Direção: BORGES, Cavi; UCHÔA, Alonquel. Rio de Janeiro: 2015.

DEUS, Zélia Amador. Os desafios da academia frente à Lei no ${ }^{0}$ 10.639/03. Revista Educação Pública Cuiabá, v. 21, n. 46, p. 229-242, maio/ago., 2012.

DIAS, Lucimar Rosa. Quantos passos já foram dados? A questão de raça nas leis educacionais. Da LDB de 1961 a Lei n. 10.639. Revista Espaço Acadêmico, n. 38, julho 2004. Disponível em: http://www.espacoacademico.com.br/038/38cdias.htm. Acesso em 28 mar. 2014. 
FANON, Frantz. Os condenados da Terra. Rio de Janeiro: Civilização Brasileira, 1979.

GOFFMAN, Erving. Estigma: notas sobre a manipulação da identidade deteriorada. 4. ed.

Rio de Janeiro: LTC, 1988.

GOMES, Nilma. Diversidade étnico-racial, inclusão e equidade na Educação brasileira: desafios, políticas e práticas. 2010. Disponível em

http://www.anpae.org.br/iberolusobrasileiro2010/cdrom/94.pdf. Acesso em 15 jun. de 2014, p. 1-13.

GONÇALVES, Luciane R. D. Representações sociais sobre educação étnico-racial de professores de Ituiutaba-MG e suas contribuições para a formação docente. 2011. 130 f. Tese (Doutorado em Educação), Unicamp, Campinas, 2011.

MUNANGA, Kabengele. Uma Abordagem Conceitual das noções de Raca, Racismo, Identidade e Etnia. In: $3^{\circ}$ Seminário Nacional Relações Raciais e Educação - PENESB, Rio de Janeiro, 2003. Anais... Rio de Janeiro, 2003. Disponível em: https://www.geledes.org.br/wpcontent/uploads/2014/04/Uma-abordagem-conceitual-das-nocoes-de-raca-racismo-dentidade-eetnia.pdf. Acesso em 07 dez. 2018.

OLIVEIRA, Lúcio O. A. Expressões de Vivência da Dimensão Racial de Pessoas Brancas: representações de branquitude entre indivíduos brancos. 2007. 137 f. Dissertação (Mestrado em Psicologia), Universidade Federal da Bahia, Salvador, 2007.

PASSOS, Joana C. As Relações étnico-raciais nas licenciaturas: o que dizem os currículos anunciados. Poiésis, Tubarão. v. 8, n. 13, p. 172 - 188, jan./jun., 2014.

PIZA, Edith. Porta de vidro: entrada para branquitude. In: CARONE, Iray e BENTO, Maria A. S. (orgs.). Psicologia social do racismo: estudos sobre branquitude e branqueamento no Brasil. Petrópolis: Vozes, 2003, p. 59-90.

QUIJANO, Aníbal. (2005). Dom Quixote e os moinhos de vento na América Latina. Estudos Avançados, 19 (55), p. 9-31, 2005.

SANSONE, Lívio. Negritude sem etnicidade: o local e o global nas relações raciais e na produção cultural negra do Brasil (trad. de Vera Ribeiro). Rio de Janeiro, Pallas, 2004.

SANTOS, Wellington Oliveira dos. Corra! E as relações inter-raciais na diáspora: para uma discussão educacional. Revista Mídia e Cotidiano, v. 12, n. 3, p. 275- 292, dez. 2018.

SANTOS, Wellington Oliveira dos. Relações raciais, Programa Nacional do Livro Didático (PNLD) e livros didáticos de geografia. 2012. 192 f. Dissertação (Mestrado em Educação), Universidade Federal do Paraná, Curitiba, 2012.

SANTOS, Wellington O; FERRARINI, Norma L. Cotas e cotistas na UFPR: opinião de estudantes ingressos antes da implantação do sistema de cotas. In: FERRARINI, Norma da Luz; RUPPEL, Dirlene (Orgs.). Inclusão Racial e Social: Considerações sobre a trajetória UFPR. Curitiba: editora UFPR, 2013, p. 145-174.

SCHUCMAN, Lia V. Branquitude e poder: revisitando o "medo branco" no século XXI. Revista da ABPN, v. 6, n. 13, p. 134-147, mar./jun. 2014. 
VALA, Jorge; COSTA-LOPES, Rui. Atitudes dos jovens face à diferença e diversidade: uma análise transnacional. Análise Social, n. 195, p. 255-275, 2010.

\section{Revisores}

\begin{tabular}{l||l} 
Língua Portuguesa & Jakeline Pereira Nunes \\
& E-mail: jakenunes.trad@gmail.com
\end{tabular}

Língua Inglesa

Ellen Daiane Cintra

E-mail: ellencintra.teacher@gmail.com

Língua Espanhola

Jakeline Pereira Nunes

E-mail: jakenunes.trad@gmail.com 